\title{
DEFLORAMENTO ANTIGO OU RECENTE?
}

\section{(CONSULTA)}

O Dr. ***, m. d. advogado no Fôro desta Capital, diric,ill-me a eonsulta constante dos dois quesitos abaixo transcriptos, acompanhada de uma copia, devidamente authenticada, do auto de exame de corpo de delicto procedido na menor E. P., branca, com 18 annos de edade, solteira, domestica, natural de São Paulo, residente á rua. n.

Feito o necessario estudo do documento remettido por copia, e devidamente ponderado o problema medico-legal proposto pelos quesitos, passo a emittir nas linhas seguintes meu desvalioso parecer.

\section{1.' QUESITO}

"No sentido medico-legal da expressão, deve-se considerar "defloramento recente" aquelle em que os peritos já encontraram cicatrizadas as lesões do hymen?"

RESPOSTA: - Não. E facil é justificar porque.

A expressão "defloramento recente" é defeituosa e merece ser proscripta da pratica. Entretanto, ainda hoje a miude empregada nos autos, tem significação propria, e precisa. RECENTE se diz o DEFLORAMENTO em que as lesões hymenaes ainda não cicatrizaram; desde que a cicatrização se deu o DEFLORAMENTO se diz ANTIGO. E' a tradição no nosso paiz entre os mais sabedores na especialidade, como resalta meridianamente do seguinte trecho de Souza Lima: "Considera-se recente a defloração até 8 dias, excepcionalmente até 10 ou 12 dias, prazo maximo durante o qual se podem encontrar, com a devida claresa, na maior parte dos casos, os signaes materiaes respectivos com os caracteres de traumatismo reconte.

Dahi por diante diz-se o "defloramento antigo, e nenhum dado habilita a discriminar epocas". (1)

E' facil de demonstrar que já antes de Souza Lima era corrente a expressão defloramento recente com o significado que lhe attribue Marcellino de Brito, no seu TRATADO ELEMENTAR DE MEDICINA LEGAL, que é de 1883, caracterizando o que chama defloramento recente, o qual escreveu: "Quando o despedaçamento $\theta$ recente, apresenta todos os caracteres de uma ferida contusa de bordas irregulares e sanguinolentas: a inflammação e a supuração, que sobrevêm, retardam a cicatrização". (2) E ainda recentemente Afranio Feixoto, com a sua admiravel lucidez, a definiu nos seguintes termos incisivos: " $E$ ' viciosa e deve ser evitada a maneira de dizer defloramento antigo ou recente, segundo os retalhos do hymen estão, on não, cicatrizados. Como ha um prazo legal para o processo por crime de defloramento (até 6 mezes) faz confusão ás autoridades uma expressão que significa, para nós medicos legistas, não serem

\footnotetext{
1) - SoUZA LIMA - Tratado de Medicina-Legal - Volume II - Rlo - 190.5 - pag. 48.

2) - MARCELLINo DE BRITTO - Tratado elementar de Medicina Legal - Rio - 1883 - pag. 74 .
} 
mais sangrentas as lesões, isto $\dot{\theta}$, recentes, mas saradas, isto $\dot{e}$, pelo menos de tres semanas. Melhor será dizer que os retalhos do hymen, as lesões do defloramento já estão, ou não, cicatrizadas" (3)

Não foi, aliás, creação brasileira. Recebemo-la, como tantos outros defeitos, da sciencia franseza.

Já o velho Devergie ensinava os "meios de distinguir se a defloração é recente ou antiga", explicando claramente: "Quando a defloração é recente, e depende de uma causa physica, offerece todos os caracteres de uma solução de continuidade das partes molles (ferida). E' rôta (a membrana) em varios retalhos; as bordas da ruptura são desiguaes, sangrentas, franjadas, mais vermelhas que o resto da membrana" e terminava: "em uma palavra, é o aspecto de uma ferida recente sobre uma membrana de pouca extensão"... accrescentando: "os labios da ferida (hymenal) cicatrizam-se mais ou menos perfeitamente e só se encontram restos da membrana hynien: então não é mais possivel dizer se o defloramento é recente ou antigo". (4)

Tardieu seguiu o mesmo ensino: "Quando recente, a ruptura do hymen apresenta todos os caracteres de uma ferida contusa de bordas vermelhas e sangrentas", chamando estes de "signaes de dePloração recente": “E' importante pesquizar a duração deste periodo de cicatrização que fornece os signaes mais certos da defloração recente". (5)

Quem percorre as lições de Brouardel sobre "Les attentats aux moeurs" (1909) verifica que a mesma orientação adoptou o grande mestre da escola de Paris e que o facto de estarem em via de cicatrizacão as lesões do hymen, a circunstancia de não estarem ainda cicatrizadas os retalhos hymenaes foi o que dominou nas diagnoses de "defloramentos de data recente" das observações que figuram no seu livro. (6)

Mais recentemente escreveu tambem Vibert "DEFLORAÇÃO RECFNTE - A defloração recente é evidentemente mais facil de reconhecer: encontra-se no hymen uma ferida viva, cujas bordas estão geralmente um pouco tumefeitas e inflammadas e são algumas vezes séde de uma ligeira suppuração". (7)

Iacassagne e Martin, da escola lionesa, falando dos "signaes do dofloramento", descrevem: "Os retalhos permanecem sangrentos 2 ou 3 dias; suppuram um pouco, cicatrizam-se. " "Após 7 ou 8 dias esta cicatrização produz-se e os traços da ruptura recente não existem mais". (8)

\footnotetext{
3) - Afranio PEIXoto - Medicina Legal - 3.* edição - Rio 3918 - pag. $15 ! 5$.

4) - DEvergie - Medicine legale theorique et pratique - T. I. - Bruxelles - 18137 - pag. 136.

5) - TARDIEU - Etade médico-legale sur les attentats aux moeurs - Septiéme edition - Paris - 1878 - pag 52.

6) - BROUARDEL - Les attentats aux moeurs - Paris - 1909 pag. 137 e seguintes.

7) - VIBERT - Précis de médécine légale - Dixiéme odition - Parí - 1921 - p: g. 379 .

8) - LACASSAgNE et MARTIN - Précés de medecine légale - Troisiéme editior - Paris - 1921 - pag. 614.
} 
Bem claro está, pois, que na medicina legal francêsa a expressão - "defloramento recente" - tem o mesmo sentido que no Brasil se lhe attribue. Não pretendo, todavia (é util accrescentar) affirnıar que os mestres allemães e italianos não tenham usado a mesma maneira de dizer no mesmo sentido. Ao contrario, essa orientação é geral e, embora menos frequente, facil seria citar, se fosse necessar:o, trechos dessa ordem, colhidos em trabalhos italianos e allemães. Para exemplo servirá um compendio italiano recente. corrente e estimado no nosso meio, o de Madia. Lá existe o seguinte passo expressivo: - "Emquanto recente, a laceração do hymen apresenta todos os caracteres de uma ferida lacero-contusa de margens deseguaes, ecchymosades, dolorosas ao tacto".

Em resumo e em conclusão: embora condemnavel por se prestar a confusões, a expressão - defloramento recente - tem significado exacto e proprio; designa aquelles casos em que as rupturas hymenaes ainda não cicatrizaram, em que as lesões do defloramento ainda não estão saradas. $\mathrm{E}$, destarte, no sentido medico-legal da expressão, não se póde considerar defloremento recente aquelle em que os peritos encontraram já cicatrizadas as lesões do hymen.

\section{2.' QUESITO}

"Pela descripção feita no auto de exame, remettido por copia, pode-se affirmar que se trata de defloramento recente?"

RESPOSTA: - Parece-me que não, desde que os dignos peritos dizem que a ruptura hymenal completa estava recem-cicatrizada (isto é, que tinha sarado a lesão hymenal) e do auto, ademais, não constam os elementos em que se basearam para estabelecer o difficilimo diagnostico de recenticidade da cicatriz hymenal. E' verdade que, no ponto, não é o auto bastante claro, prestando-se até a confusões lamentaveis. Com effeito, o auto limita-se, na descripção das lesões verificadas, ao seguinte: "apresentando (o hymen) uma ruptura completa, de bordas recem-cicatrizadas e ecchymosadas, situada no quadrante inferior esquerdo". $\mathrm{E}$ "deante do exposto" $\dot{\theta}$ que concluiram os dignos peritos que "E. P. estava deflorada de epoca recente, que podia coincidir perfeitamente com a data pela mesma referida".

Porei á margem os perigos dessa approximação diagnostica ("coincidir com a data pela mesma referida") tão grande, em caso em que os subsidios offerecidos pelas lesões para juizo pericial, pelo que consta do auto, não deviam ser muitos, nem, ao menos, bastantes.

Difficilmente, porém, comsigo entender como os retalhos já ci. catrizados ainda estavam "ecchymosados". Se a ruptura tinha as bordas cicatrizadas, embora recentemente, é que a ferida lacerocontusa, nellas existente, tinha "fechado". Quando se diz que a lesão hymenal estava cicatrizada, affirma-se que sarou, que cessaram os phenomenos que succedem ao trauma e que caracterizaram o que * chamou defloramento recente. Como, pois, estando saradas, ainda estavam as bordas do hymen ecchymosadas? Note-se que o auto

9) - MADIA - Trattato di medicina legale - Nona edizione - Napoli -- 1920 - pag. 436. 
não điz que as bordas estavam em via de cicatrização, não affirma que a cicatrização estava a terminar-se, mas assegura que já havia torminado, que o processo cicatricial já estava ultimado. A ferida do hymen é, no caso, umá lesão lacero-contusa e, ao lado da irregularidade, a existencia de ecchymoscs nas bordas da ruptura, o serem as bordas ecchymosadas $\epsilon$ uma calacteristica essencial da lesão antes de cicatrizar. Como, assim, admittir que existissem ainda ecchymoses provenientes da ruptura e estivesse esta já cicatrizada, recentemente embora?

So ha duas hypotheses plausiveis: ou diagnosticaram os dignos peritos cicatrização onde não havia e quando não deviam fazel-o (porque os labios da ferida estavam ainda ecchymosados): ou, então, tendo encontrado nas bordas dos retalhos linha cicatricial visivel, manifesta, observaram ecchymoses, que, nesta hypothese, deviam ser posteriores á ruptura cicatrizada, naturalmente provenientes de an trauma produzido tempos depojs della, possivelmente pela attricção do retalho.

A primeira hypothese não é acceitavel; não é admissivel suspeitar sequer que houvessem commettido os dignos peritos do exame do corpo de delicto tal erro de technologia. A segunda, perfeitamente possivel e verificavel praticamente, não probaliza tambem a dignose de defloramento recente. Tendo os peritos affirmado que a ruptura estava cicatrizada, forçosa é a conclusão de que o defloramento nãc era recente, no sentido medico-legal da expressão.

Resta saber se é possivel a dignose de recenticidade da cicatriz hymenal, tornando acceitavel determinação mais approximada da epoca do trauma. Possivel é, não ha duvidas a respeito. Mas constitue diagnose de extraordinaria difficuldade, a mais inçada de perigos de confusão, de erros num€rosos e frequentes. Para obviar estes erros mandam as bôas regras technicas só effectual-a nog casos em que dispuzér o perito de varios elementos de prova, colhidos quer no estado geral da offenàida, quer no exame local dos orgams sexuaes, no hymen, como nas demais porções da vulva. Taes elementos não constam do auto remettido por copia. Toda a descripção dos retalhos hymenaes resume-se no trecho que acima cite1. Nada mais de anormal notaram os peritos na membrana, no clitoris, na furcula, na fossa navicular, etc.

A circumstancia de não estar "o canal vaginal", "muito alargado", (o que denuncia que estava yelo menos um pouco alargado) sobre vaga, nenhum valor tem na diagnose do tempo do defloramento.

Não vejo, pois, no auto, elementos que possam motivar juizo mais approximado do que aquella ciţda conclusão eschematica da tradição dos nossos medicos legistas.

E' o meu parecer, salvo melhor juizo.

OSCAR FREIRE.

Certifico que tenho empreg, reconstituinte VIDAN em cui. calcio, glycerophosphato de ma: -om bons resultados, em minha clinica o nula se associam o hypophosphito de io, glycerina, kola e arsenico. a) DR. CELESTINO BOURROLLL 